\title{
EDITORIAL
}

\section{Between solitude and loneliness: A meditation}

Who knows what true loneliness is - not the conventional word but the naked terror? To the lonely themselves it wears a mask. The most miserable outcast hugs some memory or some illusion. Joseph Conrad 1857-1924 Under Western Eyes (1911), Part I, Ch. 2

Death is the extreme of loneliness that is what is so important. Loneliness is absolute. It is an illusion to imagine anything else.

Cries \& Whispers, Ingmar Bergman, 1973

The experience of death, although universal is each time unique. Some look forward to it, others fear it, some try to escape. In the literature there are many words that are approximations to death-awareness or death-anticipation. Words include: distress, demoralization, terror, dignity, meaning, spiritual, peace, acceptance, and isolation. A word that has found little mileage in the palliative care and psycho-oncology literature is loneliness. The epigrams however would suggest that loneliness is an integral part of death.

Loneliness by its nature is a private and hidden feeling and may be difficult to distinguish clinically from depression, anxiety, and boredom. Loneliness is similar to, although distinct from, Yalom's concept of isolation (Yalom, 1980).

Tools have been validated to measure depression, dignity, and demoralization, but none reliably for loneliness. The problem may be in finding the precise words to translate the feeling of loneliness. Loneliness is not a symptom we typically look for in psycho-oncology or palliative care. It is not in DSM-X nor ICDN-Y. It is however found in bars, Facebook, Twitter, shopping malls, holiday resorts, and crowds at sporting events. It is common.

Loneliness has been described as a gap between desired and actual social connectedness, and is caused by low self-esteem, shyness, fear of negative evaluation, and poor social skills. Lack of human company is not the sole cause of loneliness. Loneli- ness may also be existential, intellectual, political, and moral.

When the terror of life-death presses irreducibly upon ones shoulders an existential or spiritual crisis may express itself as loneliness. Spiritual healers recommend retreats, solitude, and withdrawal in order to develop resilience to existential loneliness. Aldous Huxley in Brave New World summed up the depth of the existential dilemma: "If one's different, one's bound to be lonely." This aspect of loneliness is the given of Yalom's existential isolation (Yalom, 1980) and Ettema's existential loneliness (Ettema, 2010).

Surrealist artists such as the American Edward Hopper in "Nighthawks" (1942) and the Australian Jeffrey Smart in "Cahill Expressway" (1962) describe painstakingly in their pictures the intense emotions of loneliness expressed as isolation, emptiness, purposelessness, and even absurdity. There is an unpaved path that connects loneliness and absurdity, and both of them undermine our existential security.

So how does Bergman connect death to loneliness? Emphatically he is not talking about a little and transient loneliness. He is describing unrequited loneliness taken to its emotional conclusion. Bergman suggests loneliness is the fear of utter aloneness in the universe, and it its extreme, life ceases to be liveable.

Conrad also commented on the significance of "true loneliness." He noted that the most intense loneliness - of "naked terror" (and of what, if not death?) - may need to be ameliorated by a comforting recollection, even of self-pity, even if it is a lie.

An extreme viewpoint is that we are always alone. It is only through crude although remarkably effective symbols (words, images, music) that one consciousness isolated within a skull can communicate with another consciousness equally isolated in a different skull. In death it is my consciousness and mine alone that will vanish. In this sense I am utterly alone when I die. There are celebrated examples of people choosing to die together in suicide pacts, for example, Stephan Zweig and his wife Charlotte. There are also many stories of murder-suicide finales. One could argue the toss, whether they died together or alone. 


\section{WHAT DOES THE LITERATURE SAYABOUT LONELINESS?}

There are few validated questionnaires on loneliness and none specific to palliative care or psychooncology. Russel in 1978 developed the UCLA Loneliness Scale with 20 questions (Russell, 1978). Rokach developed a Loneliness Questionnaire consisting of 86 yes-no questions (Rokach, 1998), which has been used in studying the coping mechanisms of the elderly and in end-of-life research (Rokach, 2007). Neither of these questionnaires has been widely used.

Hawkley showed a high association between loneliness and pre-disease pathways, and subsequent morbidity and mortality of chronic diseases such as cancer, cardiovascular disease, and drug and alcohol abuse (Hawkley, 2003).

Cacioppo postulated that loneliness evolved as a protective psychological mechanism to encourage individuals to "build social connections" to increase the likelihood of survival (Cacioppo, 2006).

Ettema used a philosophical background to categorize loneliness into social, emotional, and existential types. Existential loneliness is characterized by a feeling of isolation, death awareness, difficulty in expressing loneliness, the opportunity to create a positive experience, and acknowledging man's lonely nature (Ettema, 2010).

Yalom divided isolation into three: interpersonal (loneliness, isolation from other individuals, personality style: schizoid, narcissistic); intrapersonal (stifles ones own feelings or desires, and accepts others' "shoulds" and "oughts"), and existential that is "an unbridgeable gulf between oneself and any other being; a separation between the individual and the world" (Yalom, 1980, p. 355), in which each enters alone and departs alone.

Yalom's and Ettema's taxonomies of isolation and loneliness are clumsy in the clinical setting. Artificially dividing up loneliness (given the overlap between the subgroups) will not help the clinician at the bedside. Loneliness is the final common pathway of many enmeshed causes and factors.

I prefer the word loneliness over isolation, for two reasons. Loneliness is a word of the street, a common human experience, and easier to identify with at the bedside. Second, loneliness has a more subjective, stronger emotional content, mainly sadness; whereas isolation is an objective description, the fact of being alone.

What distinguishes between someone who profits by the intimacy of solitude, and someone who is distressed by the loneliness of isolation?

Solitude in a person near the end of life conjures images of comfort with oneself, dignity, selfknowledge, and spirituality, an acceptance of loss, death and regret. This may be the result of a lifetime of arduous mental effort, a recently acquired understanding, or a trait established early in life. Another type of solitude may be the expression of social phobia or other psycho-pathology.

Silence is often a part of solitude. In people with advanced disease silence can be a diagnostic between solitude and loneliness. To be in solitude and bear the silence, even to enjoy it; to hear ones thoughts, follow them, smile ironically to self at some embarrassment, but always to sit quietly and know ones own mind. Or does the silence drive one to anxious distraction, and one feels forced to rush off to the disco, a movie, or the pub, to fill in the fearful silence that lies between the ears and the heart? This is the terror of loneliness. Schiller in the song "Solitude" put it well: "When everything has left you, you are alone; when you have left everything behind, there is solitude."

Acceptance of death is learning to be alone, in preparation for the ultimate aloneness, hence loneliness is a symptom of death. Loneliness has a sad and poignant ring to it. A person who never married - or desperately wanted to have children but could not, goes home alone and lonely.

\section{HAVING DESCRIBED LONELINESS, ARE THERE THERAPIES?}

Rather than going directly for the jugular and discussing death, dying and the life hereafter with patients, it may be better to shoo away loneliness with companionship, empathy and presence. Is not this what Yalom meant when he said: "it is the relationship that heals"? (Yalom, 1980; p. 401) And in those moments and for a period after the interaction, if the loneliness is kept at bay with, memory or illusion, then this is a successful therapy.

A patient who is alone, should he be left alone? He might be in denial, in ignorance, in contentment or lonely. We should ask the patient whether they want to be alone or not; and if so, why so; and if alone, from whom. If they elect to be alone, we must diagnose whether it is pathological withdrawal or peaceful solitude.

Finally, loneliness can serve as a nidus for self-exploration. The distress of loneliness may provide a stimulus for emotional and spiritual creativity. Feeling lonely is a chance to reflect on what it means to be by yourself, and indeed, to be yourself.

\section{REFERENCES}

Cacioppo, J.T., Hawkley, L.C., Ernst, J.M., et al. (2006). Loneliness within a nomological net: An evolutionary perspective. Journal of Research in Personality, 40, 1054-1085. 
Ettema, E.J., Derksen, L.D. \& van Leeuwen, E. (2010). Existential loneliness and end-of-life care: A systematic review. Theoretical Medicine and Bioethics., 31, 141-169.

Hawkley, L.C. \& Cacioppo, J.T. (2003). Loneliness and pathways to disease. Brain, Behavior, and Immunity, 17, S98-S105.

Rokach, A. \& Brock, H. (1998). Coping with loneliness. Journal of Psychology, 132, 107-127.

Rokach, A., Matalon, R., Safarov, A., et al. (2007). The loneliness experience of the dying and of those who care for them. Palliative and Supportive Care, 5, 153-159.

Russell, D., Peplau, L.A. \& Ferguson, M.L. (1978). Developing a measure of loneliness. Journal of Personality Assessment, 42, 290-294.
Yalom, I. (1980). Existential psychotherapy. New York: Basic Books.

SIMON WEIN, M.D Pain and Palliative Care Service Davidoff Cancer Center Rabin Medical Center 39 Jabotinsky Street Peatach Tikvah Israel, 49100

E-mail: simonwe@clalit.org.il 